\title{
UPAYA ORANG TUA DALAM MENGANTISIPASI BAHAYA NARKOBA DIKALANGAN REMAJA DESA SALAMBUE KECAMATAN PADANGSIDIMPUAN TENGGARA
}

\author{
Nur Cahaya Nasution \\ Psikologi Pendidikan Islam, UIN Sunan Kalijaga Yogyakarta \\ Email: nurcahaya1711@gmail.com
}

\begin{abstract}
Salambue Village is a village that is quite vulnerable to drug activities. It is evident that dealers, dealers and drug users are increasing and increasing. This study will explore: 1) The Condition of Adolescents Who Misuse Drugs in Salambue Village, 2) Parents' Efforts to Anticipate Narcotics Hazards among Adolescents in Salambue Village II, 3) Parental Obstacles and Challenges in Anticipating Narcotics Hazards in Salambue Sub-District Youth Adolescents Padangsidimpuan Tenggara. This research is qualitative research using descriptive methods. Data collection is done by observation and interview techniques. The results showed that: 1) The Condition of Adolescents Abusing Narcotics in Salambue Village was very alarming because it resulted in psychiatric disorders (crazy), 2) Parents' efforts to anticipate the danger of narcotics among Salambue Villagers included: continuous parental advice, sending their children to school to Pondok Pesantren, punishments that educate, equip children with religious knowledge, children are preoccupied with positive activities, limit child interaction, spend time with children and create comfort in the household so that children feel at home. 3) Obstacles and Challenges of Parents in Anticipating the Dangers of Narcotics in Adolescents Salambue Village, South Padangsidimpuan Subdistrict, is: limited parental time for children, limited parental knowledge about drugs, and village conditions for drug emergency.
\end{abstract}

Keywords: Parent Efforts, Anticipating, Dangers of Narcotics, Adolescents.

\begin{abstract}
Abstrak
Desa Salambue merupakan sebuah desa yang cukup rawan dengan aktivitas narkoba. Terbukti bahwa para bandar, pengedar dan pengguna narkoba semakin meningkat dan bertambah banyak. Penelitian ini akan mengeksplorasi: 1) Kondisi Remaja yang Menyalahgunakan Narkoba di Desa Salambue, 2) Upaya-upaya Orangtua dalam Mengantisipasi Bahaya Narkoba dikalangan Remaja di Lingkungan II Desa Salambue, 3) Hambatan dan Tantangan Orangtua dalam Mengantisipasi Bahaya Narkoba di Kalangan Remaja Desa Salambue Kecamatan Padangsidimpuan Tenggara. Penelitian ini adalah penelitian Kualitatif dengan menggunakan metode deskriptif. Pengumpulan data dilakukan dengan teknik observasi dan interview (wawancara). Hasil penelitian menunjukkan bahwa: 1) Kondisi Remaja yang Menyalahgunakan Narkoba di Desa Salambue sangat memprihatinkan karena sampai mengakibatkan gangguan kejiwaan (gila), 2) Upaya-upaya Orangtua dalam Mengantisipasi Bahaya Narkoba dikalangan Remaja Desa Salambue, meliputi: nasehat orangtua secara kontinu, menyekolahkan anak ke Pondok Pesantren, hukuman yang mendidik, membekali anak dengan ilmu agama, anak disibukkan dengan kegiatan positif, membatasi pergaulan anak, meluangkan waktu bersama anak dan menciptakan kenyamanan dalam rumah tangga agar anak betah tinggal di rumah. 3) Hambatan dan Tantangan Orangtua dalam Mengantisipasi Bahaya Narkoba di Kalangan Remaja Desa Salambue Kecamatan Padangsidimpuan Tenggara, adalah: waktu luang orangtua yang terbatas untuk anak, pengetahuan orangtua yang terbatas tentang narkoba, dan kondisi desa yang darurat narkoba.
\end{abstract}

Kata Kunci: Upaya Orang tua, Mengantisipasi, Bahaya Narkoba, Remaja 


\section{PENDAHULUAN}

Pecandu dan pengguna narkoba saat ini tidak hanya di kalangan dewasa, bahkan sudah memasuki kalangan remaja dan kalangan anak- anak. Di kalangan anak-anak dan remaja pengguna narkoba di karenakan pembinaan anak dan remaja yang kurang perhatian dari orang tua dan keluarga. ${ }^{1}$ Namun, mirisnya saat ini korban pengguna narkoba mayoritas para remaja yang berasal dari keluarga yang broken-home. Keluarga yang broken-home adalah cermin dari orang tua (ayah) sebagai kepala keluarga yang tidak bertanggung jawab kepada anggota keluarganya. ${ }^{2} \mathrm{Hal}$ ini menyebabkan anak tidak terkendali dan salah bergaul dengan orang yang sudah terlibat narkoba. Problem inilah menurut hemat peneliti yang menjadi dasar seorang remaja terlibat kasus narkoba.

Desa Salambue adalah satu di antara beberapa desa/kelurahan yang terdapat di Padangsidimpuan Tenggara. Kenyataan pahit yang dirasakan adalah desa Salambue ini merupakan desa yang cukup rawan dengan aktivitas narkoba, baik dari para bandar dan pengedar; bahkan pemakai narkoba semakin meningkat dan bertambah banyak. Lebih mengerikan lagi, bahwa di suatu malam kepolisian pernah mengepung rumah seorang warga yang dijadikan sebagai tempat transaksi dan pesta narkoba. Dalam pengepungan tersebut, Polisi sempat melepaskan tembakan, namun pengedar yang menjadi target berhasil melarikan diri. Meskipun demikian, pelaku narkoba ini tidak pernah jera dalam menjalankan pekerjaan haram tersebut, justru semakin bertambah banyak yang menjadi korban narkoba. Sepertinya di daerah ini terdapat kaderisasi yang dilakukan oleh para pelaku narkoba ini, sehingga jumlah mereka semakin bertambah. ${ }^{3}$ Keterangan tersebut dibenarkan oleh Suryanto selaku oknum polisi di Polres Kota Padangsidimpuan ketika diwawancarai oleh peneliti. ${ }^{4}$

Kenakalan remaja di desa Salambue terus berkembang mulai dari anak-anak, remaja bahkan sampai dewasa sudah mulai mendekati narkoba. Mereka menghalalkan segala cara demi memperoleh barang haram tersebut. Situasi ini menyebabkan warga semakin resah dan berpikir panjang jika ingin meninggalkan rumah, karena kondisinya sudah tidak aman lagi. Banyak tetangga yang kehilangan mulai dari peralatan rumah tangga, pakaian bahkan "sandal jepit". Hal ini mereka lakukan hanya untuk memenuhi kecanduan atau ketergantungan mereka terhadap 66.

15ofyan S. Willis, Problematika Remaja dan Pemecahannya (Bandung: Angkasa, 1993), hlm. 60-

${ }^{2}$ Bimo Walgito, Bimbingan Konseling Islam (Yogyakarta: CV. Andi, 2010), hlm. 215-218.

${ }^{3}$ Observasi Peneliti selaku warga desa Salambue yang sejak lahir bertempat tinggal di desa Salambue, khususnya Lingkungan II desa Salambue dan Hasil Wawancara.

${ }^{4}$ Suryanto, Polisi Kota Padangsidimpuan, Wawancara, (Selasa, 23-05-2017, 15.45 WIB). 
narkoba tersebut. Bukan hanya melakukan aksi pencurian, perkelahian bahkan penentangan serta melawan orangtua sudah mereka anggap sebagai hal yang biasa. Karena sudah ketergantungan narkoba, maka mereka melakukan apa saja untuk mendapatkan barang haram tersebut.

Abdur Rahman Batubara S.Pd.I, selaku aparat desa Salambue juga menyatakan bahwa kondisi remaja di desa Salambue yang terlibat dalam penyalahgunaan narkoba saat ini semakin rawan dan semakin merajalela. ${ }^{5}$ Banyak anak yang menghalalkan berbagai cara demi memenuhi kebutuhannya terhadap narkoba. Melawan orangtua sudah menjadi hal yang biasa mereka lakukan. Bagi mereka, asalkan bisa mendapatkan narkoba, perbuatan apapun dilakukan tanpa peduli dengan nasihat dan bimbingan orangtuanya. Menurut keterangan beliau, warga yang diketahui terjerumus dalam penyalahgunaan narkoba berkisar 10 orang. $^{6}$ Keterangan ini diperkuat oleh pernyataan Ahmad Faisal Rangkuti selaku Kepala Desa Salambue, bahwa jumlah warga yang sudah tertangkap polisi karena terlibat dalam kasus penyalahgunaan narkoba \pm 10 orang. Namun, beliau menjelaskan bahwa data warga yang dimaksud belum tercatat di dokumen pemerintahan desa Salambue. ${ }^{7}$ Pernyataan Kepala Desa tersebut diperjelas lagi oleh ibu Ade Putri selaku ajudan kepala lapas Salambue. Ketika diwawancarai, beliau mengatakan bahwa warga desa Salambue yang menjadi narapidana korban penyalahgunaan narkoba berkisar 15 orang. ${ }^{8}$ Namun, beliau tidak menunjukkan data tertulis tentang namanama narapidana yang dimaksud.

Berdasarkan pengamatan peneliti, desa Salambue merupakan desa yang rawan dengan narkoba dilihat dari para bandar, pengedar, pemakai yang semakin banyak dan terus meningkat. Hal ini sejalan dengan hasil wawancara kepada Kepala desa Salambue yaitu Bapak Ahmad Faisal Rangkuti, beliau mengatakan bahwa saat ini desa Salambue bisa dikatakan sebagai "sarang narkoba", karena tidak hanya pemakai, pengedar bahkan bandar banyak berkeliaran dimana-mana. Tidak heran jika polisi sering melepas tembakan di desa Salambue, karena rumah warga juga ada yang dijadikan sebagai tempat transaksi dan pesta narkoba. ${ }^{9}$

Beranjak dari latar belakang masalah tersebut, maka peneliti ingin menelusuri lebih mendalam tentang masalah tersebut dengan melakukan penelitian ini.

${ }^{5}$ Abdurrahman Batubara, S.Pd.I, Pengurus NNB, Wawancara (Salambue: Rabu, 29-12-2016, 13.45 WIB).

${ }^{6}$ Abdurrahman Batubara, S.Pd.I, Pengurus NNB, Wawancara (Salambue: Rabu, 29-12-2016, 13.45 WIB).

${ }^{7}$ Ahmad Faisal Rangkuti, Kepala Desa Salambue, Wawancara (Salambue: Senin, 27-12-2016, 18.30 WIB). WIB).

${ }^{8}$ Ade 'putri, Ajudan Kepala Lapas Salambue, Wawancara (Salambue: Senin, 22-05-2017, 08.45

${ }^{9}$ Ahmad Faisal Rangkuti, Kepala Desa Salambue, Wawancara (Salambue: Rabu, 08-03-2016, 19.30 WIB). 


\section{A. Metodologi Penelitian}

Jenis penelitian ini adalah penelitian kualitatif metode deskriptif. Peneliti membuat suatu gambaran kompleks, meneliti kata-kata, laporan terinci dari pandangan informan, dan melakukan studi pada situasi yang alami di lapangan penelitian. ${ }^{10}$ Dengan demikian metode ini ditujukan untuk mendeskripsikan upaya yang dilakukan orang tua dalam mengantisipasi bahaya narkoba di kalangan remaja desa Salambue Kecamatan Padangsidimpuan Tenggara.

Subjek dalam penelitian ini adalah orang tua yang memiliki anak remaja di Lingkungan II desa Salambue yang berumur 13-15 tahun. Kemudian untuk memperoleh subjek yang dimaksud, penetapan unit analisis dilaksanakan secara purposive sampling. Adapun karakteristik informan penelitian ini adalah orangtua yang memiliki anak remaja yang berumur 13-15 tahun di Lingkungan II desa Salambue.

Sumber data penelitian ini terdiri atas sumber data primer dan data sekunder. Sumber data primer adalah sumber data pokok yang dibutuhkan dalam penulisan penelitian ini yaitu orangtua yang memiliki anak remaja yang berusia 13-15 tahun di Lingkungan II desa Salambue Kecamatan Padangsidimpuan Tenggara. Sedangkan sumber data sekunder adalah sumber data pelengkap yang dibutuhkan dalam penelitian ini, yaitu remaja yang berada di Lingkungan II desa Salambue Kecamatan Padangsidimpuan Tenggara yang berumur 13-15 tahun beserta tokoh masyarakat yang berada di Desa Salambue Lingkungan II Kecamatan Padangsidimpuan Tenggara. ${ }^{11}$

Untuk mengumpulkan data yang dibutuhkan dari lapangan penelitian digunakan instrumen pengumpulan data, yaitu: Observasi dan Wawancara. Dalam penelitian ini teknik observasi yang di lakukan peneliti adalah observasi non partisipan (observasi yang dilakukan dengan tidak melibatkan peneliti sebagai pelaku. Jadi, peneliti hanya mengamati kegiatan yang berkaitan dengan upaya orang tua saja tanpa ada ikut campur tangan peneliti di lapangan penelitian. Hal ini bertujuan agar proses dan fenomena yang diteliti berjalan sesuai apa adanya. Sedangkan untuk wawancara, peneliti menerapkan wawancara mendalam (deep interview) dimana peneliti mengajukan pertanyaan secara langsung dengan subjek

10Suharsimi Arikunto, Prosedur Penelitian Suatu Pendekatan Praktik (Jakarta: PT. Rineka Cipta, 2006), hlm. 197.

${ }^{11}$ Suharsimi Arikunto, Manajemen Penelitian (Jakarta: Rineka Cipta, 2003), hlm. 125. 
penelitian dan menanyakan berbagai hal yang sesuai dengan pedoman wawancara yang telah dibuat. ${ }^{12}$

\section{UPAYA ORANGTUA DALAM MENGANTISIPASI BAHAYA NARKOBA DI KALANGAN REMAJA DI LINGKUNGAN II DESA SALAMBUE KECAMATAN PADANGSIDIMPUAN TENGGARA}

Desa Salambue yang darurat narkoba, telah menjadi bahan pikiran bagi seluruh warga Salambue. Para orangtua berupaya keras untuk mengantisipasi penyimpangan sosial tersebut agar tidak berkembang, bahkan kalau bisa dibinasakan sampai ke akar-akarnya. Adapun langkah awal yang diambil oleh para orangtua adalah melakukan upaya preventif (pencegahan) terhadap anak remaja mereka, agar jangan sampai terlibat dengan dunia narkoba. ${ }^{13}$

Berdasarkan hasil wawancara peniliti terhadap para orangtua remaja di desa Salambue, membuktikan bahwa para orangtua selalu melakukan upaya pencegahan agar anaknya tidak terjerumus ke dalam narkoba. Adapun beberapa upaya yang dilakukan oleh orangtua remaja di desa Salambue, agar anaknya terhindar dari penyalahgunaan narkoba adalah sebagai berikut:

\section{a. Nasehat Orangtua Secara Kontinu}

Bapak Agus Salim Lubis mengungkapkan kepada anaknya bahwa orang yang terjerumus ke dalam narkoba adalah orang yang telah siap kehilangan segalanya, yakni keluarga, kerabat, sahabat, dan teman-teman. Mengapa tidak, secara berkesinambungan orang tersebut akan dijauhi dan dikucilkan oleh masyarakat, di samping itu dengan penyalahgunaan narkoba akan memperpendek usia. Dengan kata lain, kalau sudah meninggal hilanglah segalanya. Oleh karena itu dikatakan orang yang terjerumus ke dalam narkoba adalah orang yang siap kehilangan segalanya. ${ }^{14}$

Dalam hal ini beliau menasehati anaknya dengan penuh kelembutan dan kasih sayang. Selain itu, berdasarkan keterangan beliau, masih ada tindakan preventif yang beliau lakukan, yakni:

1) Mengarahkan dan memberikan nasehat kepada anaknya agar tidak bergaul dengan para pengguna narkoba. Dengan kata lain, dia membatasi pergaulan anaknya sebisa mungkin.

2) Menghindari kekerasan dalam keluarga khususnya terhadap anak, sebab hal tersebut bisa menimbulkan rasa tidak hormat kepada orangtua.

\footnotetext{
${ }^{12}$ Ibid.

${ }^{13}$ Observasi Peneliti selaku warga desa Salambue yang sejak lahir bertempat tinggal di desa Salambue, khususnya Lingkungan II desa Salambue dan Hasil Wawancara.

${ }^{14}$ Agus Salim Lubis, Orangtua dari Ibnu Lubis Remaja di Desa Salambue, wawancara (Salambue: Sabtu, 25-02-2017, 08.55 WIB).
} 
3) Selaku orangtua harus bisa meluangkan waktu untuk anak, memberikan kasih sayang kepada mereka adalah hal yang sangat istimewa bagi anak. Dengan begitu anak akan berada dalam pengawasan kita selaku orangtua, dan kesehariannya berada di sekitar rumah dan tidak terlibat dengan pengguna narkoba.

4) Langkah terakhir, jika lingkungan semakin berbahaya dan tidak teratasi (dengan poin-poin sebelumnya), lebih baik pindah dan cari lingkungan baru yang lebih aman bagi anak. Dengan begitu si anak akan terhindar dari bahaya narkoba. ${ }^{15}$

Sejalan dengan keterangan Lanni Batubara juga tidak jauh berbeda dengan metode yang dilakukan oleh informan sebelumnya. Beliau mengatakan bahwa, upaya preventif yang ia lakukan kepada anaknya agar terhindar dari penyalahgunaan narkoba adalah memberikan nasehat secara kontinu. Adapun nasehat yang beliau ungkapkan kepada anaknya adalah:

"nak, sebisa mungkin janganlah berteman dengan mereka (pengguna narkoba) ya nak, kalaupun mau berteman dengan mereka, disini sajalah ya nak, di hadapan ibu dan ayahmu. Jika diajak pergi oleh mereka kemana pun, katakan "tidak" dengan cara yang sopan ya nak. Ibu dan ayah sangat sayang sama kamu nak, ibu tidak ingin sesuatu yang buruk terjadi padamu."16

\section{b. Menyekolahkan Anak ke Pondok Pesantren}

Upaya ini dilakukan oleh ibu Armiah Hannum Nasution. Selain memberikan nasehat secara kontinu kepada anaknya, upaya yang dilakukan oleh beliau adalah dengan menyekolahkan anak remajanya ke Pondok Pesantren. Menurut beliau, dengan cara seperti itu si anak dapat terhindar dari pengaruh narkoba. Kemudian dia juga akan memperoleh ilmu agama yang membentengi diri dari rayuan para pengguna narkoba yang datang dari lingkungannya. ${ }^{17}$

\section{c. Hukuman yang Mendidik}

Sebagaimana uraian sebelumnya, dikatakan bahwa bapak Asrul Siregar membatasi nasehat yang diberikan kepada anaknya berkisar dua atau tiga kali saja. Jika masih melawan barulah di hukum, dipukulpun boleh asalkan si anak bisa berubah. ${ }^{18}$ Cara yang sama juga dilakukan oleh bapak Guslan Nasution, beliau

${ }^{15}$ Agus Salim Lubis, Orangtua dari Ibnu Lubis Remaja di Desa Salambue, wawancara (Salambue: Sabtu, 25-02-2017, 08.55 WIB).

${ }^{16}$ Lanni Batubara, Orangtua dari Uskan Hidayat remaja di Desa Salambue, Wawancara (Salambue: Minggu, 26-02-2017, 18.00 WIB).

${ }^{17}$ Armiah Hannum Nasution, Orangtua dari Muhammad Roy Afriansyah Nasution remaja di Desa Salambue, Wawancara (Salambue: Sabtu, 25-02-2017, 19.55 WIB).

${ }^{18}$ Asrul Siregar, Orangtua dari Rizky Siregar remaja di Desa Salambue, Wawancara (Salambue: Minggu, 26-02-2017, 10.55 WIB). 
mengatakan bahwa ia sangat tegas dalam mendidik anaknya. Jika anaknya tidak mengindahkan arahan dan nasehatnya, si anak akan mendapatkan hukuman berupa pukulan dengan harapan si anak dapat berubah. Selain itu, beliau juga meminta pertolongan dan kerjasama dengan hatobangon, ${ }^{19}$ alim ulama ${ }^{20}$ dan pemerintahan desa Salambue untuk membantu memberikan arahan dan nasehat kepada anaknya.

\section{d. Anak disibukkan dengan Kegiatan Positif dan Bimbingan Ilmu Agama.}

Upaya ini dilakukan oleh Ibu Nurmila, beliau mengatakan bahwa trik untuk menghindarkan anaknya dari bahaya narkoba adalah selain memberikan nasehat yang kontinu, si anak juga harus disibukkan dengan aktivitas yang bermanfaat. Seperti memasukkan anaknya ke grup bimbel, les computer, kesenian, menyuruh anak untuk belajar mengaji dimalam hari. Dengan aktivitas yang begitu padat dan bernilai positif, si anak akan terhindar dari bahaya narkoba. ${ }^{21}$

\section{e. Membatasi Pergaulan Anak}

Sebagaimana hasil wawancara peneliti dengan para informan di atas, menunjukkan bahwa bapak Agus Salim Lubis dan ibu Lanni Batubara telah melakukan tindakan membatasi pergaulan ankanya. Contoh dari membatasi pergaulan anak, sebagaimana diungkapkan oleh pak Agus Salim Lubis adalah berupa nasehat (larangan bergaul kepada para pengguna narkoba), meluangkan waktu dan memberikan kasih sayang kepada anak sehingga tidak ada waktu bagi mereka untuk bergaul dengan para pengguna narkoba.

\section{f. Meluangkan Waktu Bersama Anak}

Sesuai hasil wawancara yang dilakukan oleh peneliti, tindakan ini dilakukan oleh bapak Agus salim Lubis, sebagaimana ungkapan beliau yakni: "Selaku orangtua harus bisa meluangkan waktu untuk anak, memberikan kasih sayang kepada mereka adalah hal yang sangat istimewa bagi anak. Dengan begitu anak akan berada dalam pengawasan kita selaku orangtua, dan kesehariannya berada di sekitar rumah dan tidak terlibat dengan pengguna narkoba”.

\section{g. Menciptakan Kenyamanan dalam Rumah Tangga Agar Anak Betah Tinggal di Rumah.}

Upaya ini dilakukan oleh ibu Nurhaida Batubara, Beliau mengatakan, selain memberikan nasehat sebagaimana yang telah dilakukan oleh informan lainnya, ia juga memberikan perhatian lebih kepada anaknya. Apabila anaknya terlambat pulang, beliau selalu menanyakan sebab keterlambatan anaknya dengan penuh

${ }^{19}$ Adapun hatobangon di Desa Salambue di antaranya Sangkot Nasution, Syukur Lubis dan Syafar Siagian.

${ }^{20}$ Alim ulama Desa Salambue di antaranya Sehat Batubara, Agus Nasution dan Syafi'i Nasution.

${ }^{21}$ Nurmila, Orangtua dari Padlan dan Rahmad Gunawan remaja di Desa Salambue, Wawancara (Salambue: Minggu, 26-02-2017, 20.20 WIB). 
kelembutan dan kasih sayang. Apapun aktivitas anaknya selalu beliau tanyakan, bagaimana di sekolah, tugas-tugas sekolah, pergaulan dengan teman sekolah, dan lain-lain. Terkait dengan pergaulan anaknya dengan para pengguna narkoba, beliau sama dengan ibu Lanni Batubara. Beliau mengatakan' "berteman dengan mereka (pengguna narkoba) boleh saja akan tetapi jangan sampai ikut-ikutan dalam aktivitas mereka yang menyimpang." 22

Upaya-upaya tersebut di atas juga dilakukan oleh informan lainnya terhadap anak-anak mereka, namun peneliti tidak cantumkan dalam tulisan ini, mengingat bahwa jawaban yang diberikan terkait dengan upaya preventif yang dilakukan orangtua dalam mengantisipasi anak agar terhindar dari bahaya narkoba adalah sama. Untuk itu peneliti beranggapan bahwa muatan sebelumnya telah mewakili jawaban dari informan yang dimaksud. Yakni bapak Asrul Siregar ${ }^{23}$ bapak Juni Lubis dan Ibu Marlina, ${ }^{24}$ bapak Kucok Batubara dan Ibu Ito Sihite, ${ }^{25}$ bapak Asrin Purba dan Ibu Minak Lubis ${ }^{26}$ serta bapak Abdul Munir Nasution dan ibu Asmaini. ${ }^{27}$

Setelah peneliti mendapatkan jawaban dari para orangtua, selanjutnya peneliti melakukan interview terhadap anak remaja yang bersangkutan. Adapun tujuannya adalah untuk membuktikan keabsahan data yang peneliti dapatkan. Adapun keterangan pertama dimulai oleh Padlan dan Rahmad Gunawan. Mereka mengatakan bahwa orangtuanya selalu menasehati mereka agar pintar memilih teman, selain itu mereka aktif dalam kegiatan sekolah, seperti bimbel, les computer dan lain-lain. Sebab, kata ayah dan ibunya semuanya lebih bermanfaat dibandingkan dengan bermain-main, apalagi berteman dengan pengguna narkoba. ${ }^{28}$ Demikian juga dengan Wardiah Purba, ia mengatakan bahwa ibu dan ayahnya selalu menasehatinya agar tidak bergaul dengan para pengguna narkoba, atau pada umumnya kepada orang-orang yang dianggap tidak baik dalam

\footnotetext{
${ }^{22}$ Nurhaida Batubara, Orangtua dari Muhammad Ihsan Koto remaja di Desa Salambue, Wawancara (Salambue: Minggu, 26-02-2017, 19.09 WIB).

${ }^{23}$ Asrul Siregar, Orangtua dari Rizky Siregar remaja di Desa Salambue, Wawancara (Salambue: Senin, 27-02-2017. 15.00 WIB).

${ }^{24}$ Juni Lubis dan Marlina, Orangtua dari Alif Alpan Lubis remaja di Desa Salambue, wawancara (Salambue: selasa, 28-02-2017, 08.30 WIB)

${ }^{25}$ Kucok Batubara dan Ito Sihite,Orangtua dari Ramadhan Batubara, remaja di Desa Salambue, wawancara (Salambue: selasa, 28-02-2017, 10.30 WIB).

${ }^{26}$ Asrin Purba dan Minak Lubis, Orangtua dari Wardiah Purba, remaja desa Salambue, Wawancara (Salmbue: Minggu 26-02-2017, 14.30 WIB).

${ }^{27}$ Abdul Munir Nasution dan Asmaini, Orangtua dari Abi Mazhab Zarkawi Nasution dan Rina Nasution, remaja di Desa Salambue, wawancara (Salambue: selasa, 28-02-2017, 11.45 WIB).

28Padlan dan Rahmad Gunawan, Remaja desa Salambue, Wawancara (Salambue: Minggu, 2602-2017, 15.03 WIB dan 18.25 WIB).
} 
kehidupannya, sambil memberikan contoh bagaimana kondisi orang yang baik dan tidak baik kepribadiannya. ${ }^{29}$

Berikutnya, Pendi mengatakan bahwa ia dididik oleh orangtuanya dengan didikan yang cukup tegas, disaat ia mengabaikan dan membantah nasehat orangtuanya, ia pasti mendapatkan hukuman dari orangtuanya. Bahkan menurut keterangannya, ia pernah digiring oleh ayahnya ke kantor polisi, dengan kondisi tangan terikat ia dimasukkan ke dalam mobil. Namun karena di perjalanan ia menangis-nangis sambil meminta maaf kepada ayahnya dan berjanji tidak akan mengulangi hal serupa, barulah ayahnya membatalkan hal tersebut. ${ }^{30}$

Berikutnya wawancara peneliti dengan Ari Sampurna. Ia mengatakan bahwa ia sama sekali tidak diperbolehkan orangtuanya untuk bergaul dengan para pengguna narkoba. Karena kamu akan diajak kepada kehidupan mereka yang rusak, sehingga kamu juga ikut rusak kata orangtuanya. ${ }^{31}$ Perlakuan yang sama juga dialami oleh Rina Mulianti Nasution, ia sangat dilarang bergaul dengan orang-orang yang tidak baik akhlaknya, kemana dan apa pun yang dikerjakannya selalu ditanyakan oleh orangtuanya. Dengan keadaan seperti itu, ia sangat takut melakukan kesalahan yang mengakibatkan ia mendapat hukuman dari kedua orangtuanya. ${ }^{32}$

Selain dari para orangtua, upaya preventif dalam menanggulangi bahaya narkoba juga dilakukan oleh pemerintahan desa Salambue. Adapun upaya yang dilakukan oleh pemerintahan desa Salambue adalah aktif melakukan sosialisasi dan penyuluhan kepada masyarakat tentang bahaya narkoba, cara menanggulangi bahaya narkoba dan peran orangtua dalam mengantisipasi bahaya narkoba. Menurut keterangan bapak Ahmad Faisal Rangkuti, Satu di antara tempat-tempat yang sering digunakan dalam pelaksanaan kegiatan ini adalah di Madrasah Ittihadul Falah Salambue. ${ }^{33}$ Tidak ketinggalan, barisan alim ulama dan hatobangon juga turut andil dalam kegiatan tersebut. Tidak hanya itu, hatobangon dan alim ulama juga aktif melakukan pengawasan dan controlling di daerah Salambue demi ketertiban desa Salambue dari bahaya narkoba. ${ }^{34}$ WIB).

${ }^{29}$ Wardiah Purba, Remaja Desa Salambue, Wawancara (Salambue, Minggu 26-02-2017, 17.00

30Pendi, Remaja desa Salambue, Wawancara (Salambue: Minggu, 26-02-2017, 09.25 WIB).

${ }^{31}$ Ari Sampurna, Remaja desa Salambue, Wawancara (Salambue: Sabtu, 25-02-2017, 20.25 WIB).

${ }^{32}$ Rina Mulianti Nasution, Remaja Desa Salambue, Wawancara (Salambue, Minggu 26-022017, 15.30 WIB).

${ }^{33}$ Ahmad Faisal Rangkuti, Kepala Desa Salambue, Wawancara (Salambue: Senin, 27-12-2016, 15.35 WIB). 20.15).

${ }^{34}$ Sangkot Nasution, Hatobangon Desa Salambue, Wawancara (Salambue: Sabtu, 25-02-2017, 


\section{HAMBATAN DAN TANTANGAN ORANGTUA DALAM MENGANTISIPASI BAHAYA NARKOBA DI KALANGAN REMAJA DI LINGKUNGAN II DESA SALAMBUE KECAMATAN PADANGSIDIMPUAN TENGGARA}

Ada beberapa hambatan maupun tantangan orangtua yang didapat berdasarkan hasil observasi dan wawancara peneliti adalah sebagai berikut:

a. Sebahagian orangtua sangat sibuk dalam aktivitas ekonomi, hampir 12 jam para orangtua sibuk bekerja dan mencari nafkah, sehingga sedikit waktu bagi mereka untuk mendidik dan mengawasi anak-anak mereka. Berdasarkan keadaan tersebut, para orangtua tidak begitu paham dengan aktivitas anakanaknya. ${ }^{35}$ Berdasarkan hal tersebut terlihat bahwa, para orangtua sedikit lemah dalam mendidik serta mengawasi anak-anak mereka.

b. Pengetahuan para orangtua terhadap narkoba sangat terbatas, bagaimana bentuknya, jenis-jenisnya, warnanya, dan baunya. Sehingga orangtua tidak tahu persis apakah anak-anaknya pernah membawa atau menggunakan narkoba. ${ }^{36}$ Pengetahuan mereka terhadap narkoba kebanyakan sebatas gejala yang ditimbulkan apabila menyalahgunakan narkoba tersebut. seperti, kecanduan, merusak tubuh, mencuri, mengakibatkan penyakit jiwa, bahkan menghilangkan nyawa orang lain. ${ }^{37}$

c. Desa salambue masih dalam kawasan darurat narkoba, ${ }^{38}$ sehingga para orangtua merasa resah terhadap pergaulan anak-anaknya. Dengan kondisi seperti itu, orangtua tetap berusaha sebisa mungkin menghindarkan anakanaknya dari bahaya narkoba, meskipun tidak banyak waktu yang mereka miliki.

${ }^{35}$ Observasi Peneliti ketika mewawancarai para orangtua remaja dan selaku warga desa Salambue yang sejak lahir bertempat tinggal di desa Salambue, khususnya Lingkungan II desa Salambue.

${ }^{36}$ Seperti: Lanni Batubara, Orangtua dari Uskan Hidayat remaja di Desa Salambue, Wawancara (Salambue: Minggu, 26-02-2017, 18.00 WIB). Oleh karena itu upaya yang beliau lakukan agar anaknya terhindar dari narkoba adalah nasehat secara berkesinambungan.

${ }^{37}$ Keterangan Sulhamid Nasution, Orangtua dari Wahyu Nasution remaja di Desa Salambue, Wawancara (Salambue: Senin, 27-02-2017, 10.15 WIB). Barangkali hal ini dipengaruhi oleh baground pendidikan para orangtua tersebut yang rata-rata hanya lulusan SD, SLTP dan SMA.

${ }^{38}$ Sebagaimana keterangan Abdurrahman satu di antara beberapa aparat desa Salambue, dan diperkuat oleh Ahmad faisal Rangkuti selaku kepala desa Salambue. 


\section{DUKUNGAN BAGI ORANGTUA DALAM MENGANTISIPASI BAHAYA NARKOBA DIKALANGAN REMAJA DI LINGKUNGAN II DESA SALAMBUE}

Para orangtua merasa terbantu dengan adanya berbagai dukungan dari luar keluarganya untuk melakukan tujuan dan maksud yang sama yakni mengantisipasi agar bahaya narkoba tidak sampai kepada anak-anak remaja mereka. ${ }^{39}$

Di antaranya, berdasarkan wawancara dengan bapak Asrul Siregar, bahwa mereka merasa terbantu dengan program yang datang dari pihak kepolisian, dimana pihak kepolisian berkunjung ke lembaga pendidikan anak-anak mereka untuk melakukan sosialisasi dan penyuluhan tentang bahaya penyalahgunaan narkoba. Kepolisian juga memberikan sejenis mandat kepada para peserta didik untuk melakukan pengawasan terhadap penyalahgunaan narkoba di lingkungan masing-masing peserta didik. Peserta didik diberikan sejenis kartu dan sertivikat, fungsinya adalah apabila si anak menjumpai prilaku penyalahgunaan narkoba di sekitar tempat tinggalnya, ia bisa melaporkan prihal tersebut ke kantor polisi. Adapun informasi dan keamanan si peserta didik dijamin oleh pihak kepolisian. ${ }^{40}$

Keterangan tersebut diperkuat oleh kepala MTsN 2 Padangsidimpuan yakni bapak Busro Effendy, tempat anaknya disekolahkan. Beliau mengatakan bahwa pihak kepolisian berkunjung ke MTsN 2 Padangsidimpuan untuk melakukan sosialisasi tentang bahaya penyalahgunaan narkoba, sekaligus membagikan kartu tanda sehat atau bebas dari narkoba. ${ }^{41}$ Mungkin hal inilah yang dimaksudkan oleh bapak Asrul Siregar. Selain di MTsN 2 Padangsidimpuan, peneliti juga melakukan kunjungan dan melakukan wawancara ke sekolah lain yang terdapat di kecamatan Padangsidimpuan Tenggara, yakni ke SMPN 8 Padangsidimpuan. Hasil wawancara peneliti dengan bapak Parada Sakti, S.Pd. selaku wakil kepala bidang kurikulum SMPN 8 Padangsidimpuan mengatakan bahwa kegiatan yang dilaksanakan oleh pihak kepolisian di MTsN 2 Padangsidimpuan, pernah juga dilaksanakan di SMPN 8 Padangsidimpuan. ${ }^{42}$

${ }^{39}$ Observasi Peneliti ketika mewawancarai para orangtua remaja dan selaku warga desa Salambue yang sejak lahir bertempat tinggal di desa Salambue, khususnya Lingkungan II desa Salambue.

${ }^{40}$ Asrul Siregar, Orangtua dari Rizky Siregar remaja di Desa Salambue, Wawancara (Salambue: Minggu, 26-02-2017, 10.55 WIB).

${ }^{41}$ Menurut keterangan Beliau kegiatan tersebut terjadi di bulan November 2016 yang lalu. Busro Effendy, S.Ag., Kepala MTsN 2 Padangsidimpuan, wawancara (MTsN 2 Padangsidimpuan: Selasa, 28-02-2017, 08.30 WIB).

${ }^{42}$ Menurut keterangan Beliau kegiatan tersebut terjadi 7 bulan yang lalu. Berarti sekitar bulan November 2016 yang lalu. Parada Sakti S.Pd., Wakil Kepala Bidang Kurikulum SMPN 8 Padangsidimpuan, wawancara (SMPN 8 Padangsidimpuan: Senin, 22-05-2017, 10.00 WIB). 
Kemudian program yang sama juga dijalankan oleh pihak pemerintahan desa. Sesuai keterangan yang diperoleh dari bapak kepala desa Ahmad Faisal Rangkuti, bahwa segenap pemerintahan desa menjalankan program sosialisasi dan penyuluhan kepada warga salambaue tentang bahaya narkoba. ${ }^{43}$ Dengan pembekalan ilmu tentang narkoba, diharapkan masyarakat dapat mencegah dan menjauhi dirinya dan keluarganya dari penyalahgunaan narkoba. Selain itu, para hatobangon, dan alim ulama juga turut membantu menjalankan dan mengawasi program tersebut. para hatobangon dan alim ulama melakukan controlling di lingkungan desa Salambue untuk mengantisipasi tindakan-tindakan menyimpang yang dilakukan oleh warga desa Salambue, khususnya terkait dengan narkoba. ${ }^{44}$

\section{PENUTUP}

Berdasarkan hasil observasi dan wawancara peneliti dengan para orangtua remaja, pemerintahan desa dan juga remaja di desa Salambue, dapat disimpulkan beberapa hal, yakni sebagai berikut:

1. Kondisi Remaja yang Menyalahgunakan Narkoba di Desa Salambue sangat memprihatinkan. Para remaja yang diketahui telah menyalahgunakan narkoba banyak melakukan tindakan yang tidak terpuji seperti: melawan orangtua, mencuri, meninggalkan rumah tanpa alasan yang jelas, putus sekolah dan mengalami gangguan kejiwaan (gila).

2. Upaya Orangtua dalam Mengantisipasi Bahaya Narkoba di Kalangan Remaja Desa Salambue Kecamatan Padangsidimpuan Tenggara, meliputi: Memberikan pendidikan kepada anak tentang bahaya narkoba; Mengarahkan dan menasehati anak agar tidak bergaul dengan para pengguna narkoba dengan penuh kelembutan dan kasih sayang; Membatasi pergaulan dan aktivitas anak di luar rumah; Menghindari kekerasan dalam keluarga khususnya terhadap anak; Meluangkan waktu untuk anak dan memberikan kasih sayang; Menyibukkan anak dengan kegiatan yang bermanfaat, seperti: grup bimbel, les computer, majlis taklim, olahraga, bakti sosial dan kesenian, Menyekolahkan anak ke lembaga Pesanteren; dan Memberikan hukuman yang sifatnya mendidik bagi anak yang tidak mengindahkan nasehat orangtua.

3. Hambatan dan Tantangan Orangtua dalam Mengantisipasi Bahaya Narkoba di Kalangan Remaja di Desa Salambue meliputi: Kesibukan mencari nafkah demi menghidup keluarga membuat sebahagian orangtua sedikit meluangkan waktu bersama anak; Pengetahuan para orangtua terhadap narkoba masih

${ }^{43}$ Ahmad Faisal Rangkuti, Kepala Desa Salambue, Wawancara (Salambue: Senin, 27-12-2016, 15.35 WIB). 20.15).

${ }^{44}$ Sangkot Nasution, Hatobangon Desa Salambue, Wawancara (Salambue: Sabtu, 25-02-2017, 
terbatas, mereka belum paham bagaimana bentuknya, jenis-jenisnya, warnanya, dan baunya; serta Desa Salambue masih dalam kawasan darurat narkoba, sehingga para orangtua merasa resah terhadap pergaulan anakanaknya.

\section{DAFTAR PUSTAKA}

AR. Sujana, Komentar dan Pembahasan Undang-Undang Nomor 35 Tahun 2009 tentang Narkotika, Jakarta: Sinar Grafika, 2011.

Abdul Razak \& Wahdi Sayuti, Remaja dan Bahaya Narkoba, Jakarta: Prenada Media Grup, 2007.

Abu Ahmadi dan Munawar Sholeh, Psikologi Perkembangan, Jakarta: PT Rineka Cipta, 2005.

Ahmad Sanusi Musthofa, Problem Narkotika-Psikotropika dan HIV-AIDS, Jakarta: Zikrul Hakim, 2012.

Bimo Walgito, Bimbingan Konseling Islam, Yogyakarta: CV. Andi, 2010.

Chairinniza Graha, Keberhasilan Anak Tergantung Orang tua, Jakarta: PT. Gramedia, 2007.

Dadang Hawari, Ilmu Kedokteran Jiwa dan Kesehatan Jiwa, Yogyakarta: PT. Dana Bhakti Prima Yasa, 1999.

Dany L. Yatim, Kepribadian Keluarga dan Narkotika, Jakarta: Arcen, 1986.

Elizabeth B. Hurlock, Psikologi Perkembangan, Jakarta: Erlangga, 2009.

Enseng Fatimah, Psikologi Perkembangan, Bandung: PustakaSetia, 2006.

Kartini Kartono, Patologi Sosial 2: Kenakalan Remaja, Jakarta: CV Rajawali, 1992.

M. Arief Hakim, Bahaya Narkoba-Alkohol: Cara Islam Mengatasi, Mencegah dan Melawan, Bandung:Nuansa, 2004.

Rifa Hidayah, Psikologi Pengasuhan Anak, Yogyakarta: UIN-Malang Press, 2009.

Salmadanis, Patologi Sosial dalam Perspektif Dakwah, Padang: Hayfa Press, 2009.

Sarlito W. Sarwono, Psikologi Remaja, Bandung: Rajawali Pers, 2010.

Sofyan S. Willis, Problematika Remaja dan Pemecahannya, Bandung: Angkasa, 1993. 
204 | Nur Cahaya Nasution

---------, Konseling Keluarga (Family Counseling), Alfabeta: Bandung, 2009.

Sumiati, Kesehatan Jiwa Remaja \& Konseling, Jakarta: Trans Info Media, 2009 